\title{
Beyond the Time Window of Intravenous Thrombolysis: Standing by or by Stenting?
}

\author{
Xinfeng Liu \\ Department of Neurology, Jinling Hospital, Nanjing University School of Medicine, \\ Nanjing, China
}

\author{
Key Words \\ Mechanical embolectomy · Angioplasty $\cdot$ Stenting
}

\begin{abstract}
Intravenous administration of tissue plasminogen activator within $4.5 \mathrm{~h}$ of symptom onset is presently the 'golden rule' for treating acute ischemic stroke. However, many patients miss the time window and others reject this treatment due to a long list of contraindications. Mechanical embolectomy has recently progressed as a potential alternative for treating patients beyond the time window for IV thrombolysis. In this paper, recent progress in mechanical embolectomy, angioplasty, and stenting in acute stroke is reviewed. Despite worries concerning the long-term clinical outcomes and increased risk of intracranial hemorrhage, favorable clinical outcomes may be achieved after mechanical embolectomy in carefully selected patients even $4.5 \mathrm{~h}$ after stroke onset. Potential steps should be prepared and attempted in these patients whose opportunity for recovery will elapse in a flash.

Copyright $\odot 2012$ S. Karger AG, Basel
\end{abstract}

\section{Introduction}

Based on the results of the National Institute of Neurological Disorders and Stroke Study (NINDS) in 1995 [1] and the Prolyse in Acute Cerebral Thromboembolism (PROACT II) study in 1999 [2], the intravenous (IV) and intra-arterial (IA) tissue plasminogen activators (tPA) for the treatment of acute stroke were approved by the US Food and Drug Administration (FDA). Since then, acute ischemic stroke within 3 and $6 \mathrm{~h}$ has been treated by IV and IA tPA, respectively. Recently, the European Cooperative Acute Stroke Study (ECASS 
III) expanded the time window of IV tPA to $4.5 \mathrm{~h}$ after stroke onset [3]. This is a giant progress in stroke treatment. However, only $3-8.5 \%$ of stroke patients could receive the tPA treatment [4]. Several studies show that 1 of 3 patients will benefit from IV tPA within $3 \mathrm{~h}, 1$ of 7 will benefit from IV tPA within $4.5 \mathrm{~h}$, and 1 of 5 will benefit from IA fibrinolysis within $6 \mathrm{~h}[5-7]$.

There are several possible reasons for the low efficiency of tPA. Not all of the patients know the exact time of stroke onset. As many as $15-25 \%$ of stroke patients are cases of wakeup strokes who are not generally offered the thrombolytic therapy according to the recommendations of the FDA [8]. Not all patients can get to the hospital within $4.5 \mathrm{~h}$. Only $20-25 \%$ of all acute stroke patients meet time window for IV thrombolysis [9] and the rate is even lower in underdeveloped countries [10]. Not all patients are suitable for receiving the IV tPA treatment even if they meet the treatment window. There are many contraindications for tPA, mainly involving a history of and/or propensity for intracerebral hemorrhage [11]. Not all of the lesions can be removed by tPA. Large proximal clots such as terminal internal carotid artery occlusion are less susceptible to IV tPA [12], especially when the thrombi are longer than $8 \mathrm{~mm}$ [13]. Only 10\% of internal carotid artery and $25 \%$ of proximal middle cerebral artery occlusions are recanalizable [14]. Not all the recanalizations are complete. Angiographically confirmed residual thrombus requiring IA therapy was found among $70 \%$ of patients who were treated with IV tPA [15]. Not all patients can benefit from successful recanalization. Downstream perfusion can be hampered by distal thromboemboli and inflammatory changes in the microcirculation which is a no-reflow phenomenon [16].

Several emerging therapies aim to overcome the limitations of tPA. First, one approach uses novel thrombolytic or defibrinogenating agents such as tenecteplase [17], desmoteplase [18], plasmin [19], and ancrod [20] to extend the time window of treatment or decrease the complications of rtPA. Second, combinatory approaches which involve using rtPA plus other agents or methods such as Argatroban [21], low-molecular-weight heparin [22], acetylsalicylic acid [23], GP IIb/IIIa inhibitors [24], and sonothrombolysis [25] are used to enhance the efficacy of fibrinolytics, prevent reclusion, and improve microcirculatory flow. There are some noninvasive methods to augment cerebral blood flow (CBF) such as noninvasive ventilator support [26], sphenopalatine ganglion stimulation [27], and partial aortic occlusion. Finally, endovascular treatments have been introduced to treat ischemic stroke to achieve local lytic application and greater rates of arterial recanalization. For the details of advantages and disadvantages, please see the recent review of Barreto and Akexandrov [28]. In this paper, we highlight the recent progress of endovascular treatments for ischemic stroke beyond the therapy time window and treatment ranges of IV tPA.

\section{Possible Mechanisms for Recanalization beyond $4.5 \mathrm{~h}$}

The major advantage of endovascular therapy is the high rate of recanalization, which is associated with good clinical outcomes [29]. The underlying mechanism of the good outcomes after recanalization is the existence of ischemic penumbra which is characterized by hypoperfusion with cellular dysfunction but not neuron death, undetermined fate, and salvage requiring successful treatment $[30,31]$. Preclinical studies have indicated that restoration of blood flow even after a long time $(>24 \mathrm{~h})$ could prevent a substantial amount of penumbra from developing infarction independent of the time to reperfusion [32]. In clinical trials, $90-100 \%$ of patients with acute ischemic stroke have penumbra in the first $3 \mathrm{~h}$ after stroke onset [33]; 75-80\% of stroke patients have penumbral tissues $6 \mathrm{~h}$ after stroke onset [34]. Even $18 \mathrm{~h}$ after stroke onset, up to one-third of patients exhibit large volumes of penumbra [35]. Markus et al. [36] observed that hypoxic tissue could survive independent of 
time for up to $48 \mathrm{~h}$ after stroke onset using a hypoxic marker and positron emission tomography (PET). The results of both basic research and clinical trials indicate that patients beyond the therapy time window could benefit from endovascular treatments. However, penumbra varies from patient to patient because it depends upon a variety of factors such as the location of vessel lesions [15], the location of ischemic lesions [37], and collateral circulation [38]. Evaluation of the penumbra and selection of the patients is necessary for endovascular treatment.

\section{Selecting Patients for Endovascular Treatment}

Thanks to great progress in neuroimaging, it is now possible to detect the penumbra and select suitable patients for endovascular treatments. Computed tomography (CT), CT perfusion, CT angiography (CTA), magnetic resonance imaging (MRI), perfusion and diffusion MRI (PWI/DWI), single-photon emission CT (SPECT), PET, and digital subtraction angiography are now used to select patients, especially those beyond the time window of tPA.

CT is a fast, widely used, and easily available method to evaluate acute ischemic stroke. It has been used to select patients for endovascular treatment in the main studies conducted to date [39-41]. The Alberta Stroke Program Early CT Scale (ASPECTS) score is a semiquantitative measure and has been confirmed to be an excellent prognostic tool [42]. In the Penumbra Pivotal Stroke Trial, the results showed that patients could benefit from endovascular treatments (3-fold compared to the control group) when the ASPECTS score was $>7$ [43]. However, the limitations of CT are that it cannot show imaging of penumbra and is less sensitive to early strokes and lesions of posterior circulation.

There are two types of CT perfusion, i.e. whole brain and dynamic CT perfusion, which could provide information of cerebral blood volume and CBF, and mean transit time and time to peak, respectively [31]. Natarajan et al. [44] used CT perfusion to guide endovascular treatments for patients more than $8 \mathrm{~h}$ after stroke onset. They found that based on cerebral blood volumes $>30 \%$ within the hemisphere compared with the contralateral hemisphere, the recanalization rate was $66.7 \%$, while $20 \%$ of patients possessed a modified Rankin Scale $(\mathrm{mRS})$ score $\leq 2$ and a 3.5-point decrease in the National Institutes of Health Stroke Scale (NIHSS) [44]. Using mechanical embolectomy in patients with lesions in less than one-third of the middle cerebral artery territory beyond the time window $(18.6 \pm 16 \mathrm{~h}$ after stroke onset), $85.7 \%$ of patients had recanalization and $42.9 \%$ of patients achieved an mRS score $\leq 2$ [45]. An ongoing clinical trial [DWI/PWI and CTP Assessment in the Triage of Wake-up and Late Presenting Strokes Undergoing Neurointervention (DAWN) trial] is evaluating the safety and efficacy of perfusion-based endovascular therapy in patients presenting more than $8 \mathrm{~h}$ after symptom onset. Preliminary data of the DAWN trial showed that $73 \%$ of the patients achieved successful recanalization and $83 \%$ of the patients had an mRS score $\leq 3$ while the rates of symptomatic intracerebral hemorrhage and mortality were 10.4 and $22 \%$ when compared to the control group, respectively [46]. There are some limitations of CT perfusion such as interobserver variability, inconsistencies between different software programs, and a lack of standardization in diagnostic criteria.

The penumbra could be estimated by MRI based on the hypothesis of mismatch between the acute PWI and DWI lesions [47]. In MR RESUE research, mechanical embolectomy was based on the presentation of penumbra detected by PWI/DWI. The results showed that acute stroke patients even beyond $4.5 \mathrm{~h}$ after stroke onset still benefited from the endovascular treatment when the mismatch was present [48]. When using DWI analysis to predict the clinical outcome of the patients, it was found that patients could only benefit from IV tPA thrombolysis when the DWI lesion volume was less than $25 \mathrm{ml}$ and the excellent outcome 
$(\mathrm{mRS} \leq 2)$ from treatment was substantially increased in patients with volumes less than 18 $\mathrm{ml}$ [49]. In anterior circulation stroke patients receiving IA thrombolysis, a DWI lesion volume greater than $70 \mathrm{ml}$ predicted poor outcomes [50]. These findings were confirmed by a subsequent study using endovascular treatment. Patients with initial DWI $>70 \mathrm{ml}$ have poor outcomes despite a $50 \%$ recanalization rate [51]. The limitations of MRI are that it needs more time to obtain the images of mismatch and there are motion artifacts and questions regarding the validity of the mismatch [52].

SPECT defines a 40-70\% reduction of the tracer signal as penumbra. However, it is semiquantitative, with radiation exposure and lack of standardized protocols; therefore, the clinical application of SPECT is very limited [53]. Another possible tool is Xenon CT, which can detect $\mathrm{CBF}$ and define the penumbra as CBF 7-30 $\mathrm{ml} / 100 \mathrm{~g} / \mathrm{min}$. Xenon CT is technically complex and not a validated way to find penumbra [54]. Some studies have applied PET to detect the penumbra; however, PET is an expensive and time-consuming technique with radiation exposure and arterial access [55].

There are some other imaging tools to suggest the existence of the penumbra and direct the endovascular treatment. Hyperintense vessels on fluid-attenuated inversion recovery imaging are frequently observed in acute ischemic stroke patients $[56,57]$, which shows the presence of large PWI/DWI mismatch in patients with proximal middle cerebral artery occlusion [58]. The existence of hyperintense vessels in distal territory of the middle cerebral artery is predictive of prolonged tissue viability on acute evaluation, and it can be used to identify patients who will benefit from treatment beyond the current thrombolysis time window [58].

Clinical profiles may also predict the outcomes after endovascular treatment. The results of a post hoc analysis of the PROACT II trial suggested that the endovascular therapy should be restricted up to the age of 80-85 years with consideration given to concomitant cardiac and other comorbidities [59]. In one study, the authors evaluated the cost and effectiveness of mechanical thrombectomy compared with standard medical therapy in patients who are ineligible to receive tPA. For patients older than 82 years of age, the treatment was only borderline cost-effective [60].

The NIHSS score is often applied to assess the outcome of stroke patients. One study found that NIHSS scores below 10 are correlated with an arterial occlusion amenable to IA treatment while NIHSS scores above 20 are linked to heightened chances of intracerebral hemorrhage [40]. The major limitations of the NIHSS are that it underestimates stroke severity, particularly for posterior circulation, and it has limited use for assessing functional status, disability, and the final outcome [61]. Hyperglycemia may be another predictor of poor outcomes [62]. Hyperglycemia in the first $48 \mathrm{~h}$ after endovascular treatments was associated with disadvantageous outcomes [63].

Some studies have developed scores to predict the clinical outcomes after endovascular treatment. The Houston IA recanalization therapy score (Houston IAT) was developed by the University of Texas Houston Stroke Center. It divided the Houston IAT score into 3 categories: 1 point for age $>75$ years; 1 point for NIHSS score $>18$, and 1 point for glucose $>150$ $\mathrm{mg} / \mathrm{dl}$. The percentage of poor outcomes using the Houston IAT score was: score of $0,44 \%$; score of $1,67 \%$; score of $2,97 \%$, and score of $3,100 \%$. Recanalization rates were similar across the scores [64]. In the MERCI and Multi MERCI trials, the totaled health risk in vascular event (THRIVE) score was applied to assess the patients. The THRIVE score, which reflects the contributions of chronic disease, age, and stroke severity, included a 10-level predictive score. Patients with a low THRIVE score of $0-2$ had good outcomes in $64.7 \%$ of cases, patients with a moderate THRIVE score of $3-5$ had good outcomes in $43.5 \%$ of cases, and patients with a high THRIVE score of 6-9 had good outcomes in $10.6 \%$ of cases [65]. Both of the scores were recently validated by another group [66]. 
Liu et al.: Endovascular Treatment of Acute Stroke

Table 1. Devices used in different studies for recanalization in patients with acute stoke

\begin{tabular}{|c|c|c|c|c|c|c|c|c|}
\hline Study & $\begin{array}{l}\text { Merci } \\
{[41]}\end{array}$ & $\begin{array}{l}\text { Multi Merci } \\
{[100]}\end{array}$ & $\begin{array}{l}\text { Penumbra } \\
{[101]}\end{array}$ & $\begin{array}{l}\text { POST } \\
{[102]}\end{array}$ & $\begin{array}{l}\text { SARIS } \\
{[94]}\end{array}$ & $\begin{array}{l}\text { Wingspan } \\
{[94]}\end{array}$ & $\begin{array}{l}\text { Solitaire } \\
{[96]}\end{array}$ & $\begin{array}{l}\text { Trevo } \\
\text { [98] }\end{array}$ \\
\hline Device & Merci & Merci & Penumbra & Penumbra & $\begin{array}{l}\text { Wingspan/ } \\
\text { Enterprise }\end{array}$ & $\begin{array}{l}\text { Wingspan/ } \\
\text { Enterprise }\end{array}$ & Solitaire & Trevo \\
\hline Sample, $\mathrm{n}$ & 141 & 164 & 20 & 125 & 20 & 12 & 20 & 13 \\
\hline Age, years & 67 & 68 & 60 & 64 & 63 & 49 & 66 & 74 \\
\hline NIHSS & 20.1 & 19 & 21 & 18 & 14 & 17 & 19 & 19 \\
\hline Hyperglycemia & none & none & none & none & none & none & none & none \\
\hline Imaging & CT & CT & CT & CT & CT & CT & CT & CT \\
\hline Time to treatment, $\mathrm{h}$ & 4.3 & $3-8$ & $\geq 3$ & 4.5 & 5.25 & 66.1 & 5.9 & 5.0 \\
\hline Recanalization, \% & 48 & 57.3 & 100 & 81.6 & 100 & 92.7 & 90 & 77 \\
\hline $\mathrm{mRS} \leq 2, \%$ & 46 & 36 & 45 & 25 & 60 & 50 & 45 & 30.8 \\
\hline Mortality, \% & 23.9 & 34 & 45 & 32.8 & 25 & 16.7 & 20 & 30.8 \\
\hline Symptomatic ICH, \% & 7.8 & 9.8 & 10 & 11.2 & 5 & 16.7 & 10 & 0 \\
\hline
\end{tabular}

$\mathrm{ICH}=$ Intracerebral hemorrhage.

\section{Selecting Devices for Recanalization}

Stroke is a heterologous-cause disease. Different causes induce the clot of cerebral vessels, such as embolism, thrombosis, and atherosclerosis [67]. To date, there are many kinds of endovascular treatment devices and each device has its own advantages and disadvantages; therefore, selecting the proper device for each patient is necessary (table 1). We divided the devices into three categories: snare-based devices, aspiration devices, and stent-based devices.

\section{Snare-Based Devices}

In the 1990s, the snare was initially used to retrieve foreign bodies from cerebral vessels, such as fracture of electrolytically detachable coils during treatment of intracerebral aneurysms [68]. Chopko et al. [69] used a 4-mm goose-neck snare through a microcatheter to snare and withdraw a clot in a 38-year-old man with near-total occlusion of the right middle cerebral artery at the M1-M2 junction. Subsequently four devices were developed to remove cerebral clots: the Microsnare (Microvena, Minneapolis, Minn., USA), the Neuronet (Guidant, Temecula, Calif., USA), the In-Time Retriever (Target, Fremont, Calif., USA), and the EnSnare (Medical Device Technologies, Gainesville, Fla., USA) [70]. The Microsnare is a $90^{\circ}$ angled loop that comes in 2-, 4-, and 7-mm diameters and can be placed through any standard 0.018-in microcatheter [71]; the Neuronet is a self-expanding nitinol basket portion tapering to a shapeable platinum-tipped wire [72]; the In-Time Retriever is a Dormiatype design that is delivered without a separate microcatheter and is opened by applying traction to the central wire that leads to foreshortening and opening of the device [73]; the EnSnare is similar to the In-Time device. In the meantime, there have been three other devices, i.e. Catch, Attactor-18, and Alligator. The Catch device consists of a self-expanding basket-like device fixed to a pusher wire [74]. The Attracter-18 device is a radiopaque distal platinum coil with a wire tip [75]. The Alligator retrieval device contains 4 small jaws mounted on a solid core shaft within a microcatheter, which once advanced from the microcatheter forms a 4-pronged grabbing device [76]. Next, the Merci clot retriever (Concentric Medical, Mountain View, Calif., USA) was developed and first approved by the FDA in 2004. The Merci device is a flexible nitinol wire with a multi-loop helix when it is advanced out of the microcatheter. There are currently V, L, and X6 series of the Merci device [41, 77]. Another retriever device approved in Europe is the Phenox clot retriever (Phenox, Bochum, 
Germany) which is a wire surrounded by a dense palisade of perpendicularly oriented stiff polyamide microfilaments [78].

Besides these devices, some researchers have tried to combine the microwire with other techniques. The LaTIS laser device uses laser technology which contains a laser at its tip to heat the clot to make it break down [79]. The Endovascular Photo Acoustic Recanalization (EPAR) laser system creates microcavitation bubbles by converting photonic energy into acoustic energy at the fiber optic tip to break the clot down [80]. The EndoWave Infusion Catheter System (EKOS) ultrasound device with a small ultrasound transducer at the tip of the device could increase the permeability of drugs into the clot to accelerate clot dissolution [81].

\section{Aspiration Devices}

The snare-based techniques generally dissolve the clots, and clot fragmentation may cause potential proximal occlusion. To overcome this potential risk, aspiration devices were developed. Initially the aspiration devices were applied to remove foreign species in the cerebral vessels, such as dialysis-related access grafts. There are four kinds of devices: the AngioJet System, the Oasis System, the Hydrolyzer, and the Amplatz device. The AngioJet System, based on the Venturi-Bernoulli effect, uses high-pressure saline jets which are introduced through orifices in the distal tip of the catheter to create a localized low-pressure zone, resulting in a vacuum effect with entrainment and dissociation of bulky thrombi [82]. The other three early systems are similar to the AngioJet System and were only experimental for acute embolic stroke $[83,84]$. Subsequently, the NeuroJet came out; it also used the Venturi effect to disrupt and aspirate the clot via a high-pressure saline jet at the distal tip that was then immediately aspirated. The system was specifically designed to remove cerebral vessel thromboemboli [83]. Recently, a new-generation neuroembolectomy device, the Penumbra System, was approved by the FDA for the treatment of acute stroke via debulking and aspiration of acute clots [85]. The Penumbra consists of 3 main components: a reperfusion catheter, a separator, and a thrombus removal ring required to remove the residual thrombus. The reperfusion catheter is used to separate the thrombus and aspirate it from the occluded vessel.

\section{Stent-Based Devices}

Angioplasty and stenting has become a widely used mechanical treatment for atherosclerosis in craniocervical vessels in China [86-89]. It was first used to treat asymptomatic patients or subacute and chronic stroke patients [90]. For acute ischemic strokes, balloonmounted stents were used in an early small cohort study until the self-expanding stent came out $[91,92]$. The NeuroForm self-expanding stent, which was designed for cerebral aneurysm, was used to treat occlusion of the middle cerebral artery after failure of thrombolysis in an acute stroke patient [93]. Then the Wingspan self-expanding stent, which is an extraflexible self-expanding stent, was approved by the FDA as the primary intervention for 20 cases of acute stroke [94]. Another self-expanding stent is the Enterprise stent, which is a new highly flexible nitinol stent with a fixed closed-cell design [95].

The Solitaire device, a laser-cut, self-expanding, split-design, closed-cell nitinol stent device, was developed to treat acute stroke [96] (fig. 1). The Aperio device, a hybrid-design stent-based clot retriever with alternating segments of small closed cells and wider hybrid cells for high flexibility, could improve vessel apposition and provide better thrombus fixation during retrieval [97]. The Trevo System is a stent-like device which can integrate the clot into the stent structure and retract the device to remove the clot from the vessel [98]. 

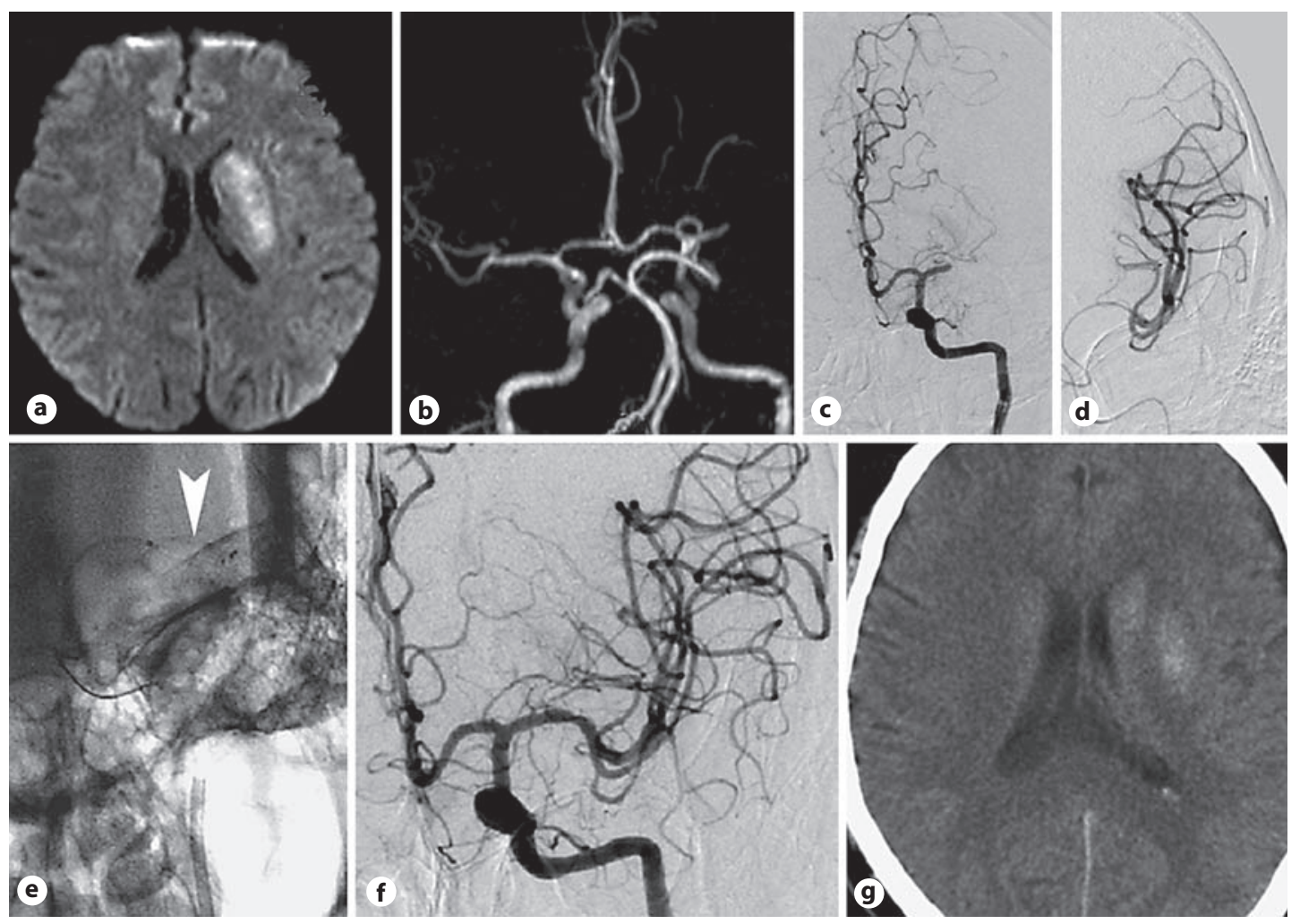

Fig. 1. A 58-year-old male with aphasia and right hemiparesis reached our hospital $6 \mathrm{~h}$ after symptom onset (NIHSS = 15). a A diffusion-weighted image showed a slightly high signal in the left insular area. b Magnetic resonance angiogram. c Digital subtraction angiography demonstrated M1 segment occlusion in the left middle cerebral artery. $\mathbf{d}$ Angiogram via a microguide indicated complete patency of the distal middle cerebral artery. e A solitaire stent was deployed (arrowhead). $\mathbf{f}$ A final angiogram of the left middle cerebral artery after retrieval of the stent showed complete recanalization of the middle cerebral artery. g CT showed a small infarction in the left internal capsule $18 \mathrm{~h}$ after recanalization. The patient was discharged 7 days later with an NIHSS score of 4 .

\section{Evidence for Mechanical Embolectomy beyond the Time Window}

There are several clinical trials in which the enrolled patients were beyond the therapy time window or indications for tPA. Based on these results, the FDA approved the Merci device and the Penumbra System to treat acute ischemic stroke.

In a phase I clinical trial of the Merci device, 28 patients with a mean age of 68 years were studied [99]. The median baseline NIHSS score was 22. The median time from onset to completion of treatment was $6.25 \mathrm{~h}$, and 6 patients presented within $3 \mathrm{~h}$ of symptom onset but had contraindications for IV tPA. One patient was treated $11 \mathrm{~h}$ after stroke onset because of a large diffusion/perfusion mismatch on MRI. Successful recanalization (thrombolysis in myocardial infarction, TIMI, grade 2 or 3) was achieved in 18 (64\%) patients. One month later, in the 13 patients who presented with moderate to severe stroke (NIHSS 10-20), 6 out of 10 revascularized patients had achieved significant recovery ( $m R S \leq 2)$ while none of the 15 patients with mild stroke (NIHSS >20) had achieved significant recovery. Though there were 12 patients suffering intracerebal hemorrhage, no symptomatic intracranial hemorrhages occurred. This study showed the safety and efficacy of cerebral embolectomy with the Merci retriever even when performed in an extended 8-hour time window. 
Then the same group expanded the number of enrolled patients to further assess the Merci retriever [41]. The mean age of 151 enrolled patients (141 in whom the device was deployed) was 67.7 years and the mean NIHSS score was 20.1. The CT scan was applied before the embolectomy. Recanalization was achieved in 48\% (68/141) of patients. Good neurological outcomes ( $\mathrm{mRS} \leq 2)$ were more frequent at 90 days in patients with successful recanalization compared with patients with unsuccessful recanalization (46 vs. $10 \%$; $\mathrm{p}<0.0001)$ and mortality was less (32 vs. 54\%; $\mathrm{p}<0.05$ ). Symptomatic intracranial hemorrhage occurred in $7.8 \%$ of patients.

To gain a better grasp of the thrombus, the new-generation Merci device L5 was developed, and the Multi MERCI trial was designed to test the L5 device versus first-generation devices [100]. The L5 retriever was used in 131 patients among 164 receiving thrombectomy at 3-8 h of stroke onset. The mean age was 68 years and the baseline NIHSS score was 19. Successful recanalization was observed in 75 of 131 (57.3\%) treatable vessels. Thirty-six percent of patients had favorable clinical outcomes (mRS 0-2) and mortality was $34 \%$. Symptomatic intracerebral hemorrhage occurred in 16 patients $(9.8 \%)$. Higher rates of recanalization and good clinical outcomes, as well as lower mortality rates, were associated with the new-generation Merci device.

The safety and performance of the Penumbra System in reducing large-vessel occlusive clots in acute stroke patients were assessed [85]. Twenty-three subjects, with a mean age of 60 years and a baseline NIHSS score of 21, were enrolled, and 21 target vessels were treated in 20 subjects using the Penumbra System. Ten patients presented more than $3 \mathrm{~h}$ after symptom onset while, of the remaining 50\% who presented within $3 \mathrm{~h}, 6$ were refractory to rtPA therapy and 4 were not eligible for thrombolytic therapy. All of the patients were successfully revascularized (TIMI $\geq 2$ ). At the 30 -day follow-up, $45 \%$ of subjects had good clinical outcomes (4-point or greater NIHSS improvement or $\mathrm{mRS} \leq 2$ ). Subjects with a higher baseline (NIHSS $\geq 20$ ) tended to have a lower probability of a good outcome compared with patients with NIHSS scores of less than 20 (27 vs. 63\%). The all-cause mortality rate was $45 \%$ (9 of 20) and 8 patients had intracranial hemorrhage ( 2 of these patients were symptomatic as defined by CT evidence of a bleeding event and a 4-point deterioration in the NIHSS score).

Then a prospective, multicenter, single-arm study (the penumbra pivotal stroke trial) was designed to further assess the safety and efficacy of the Penumbra System [101]. A total of 125 patients were enrolled and treated using the Penumbra System. The mean age was 63.5 years and the baseline NIHSS score was 17.6; 33 patients had a higher score $(\geq 20)$. Subjects within $3 \mathrm{~h}$ of symptom onset were ineligible or refractory to tPA therapy. CT scan was used to evaluate patients before the thrombectomy. The rate of successful recanalization was $81.6 \%$ (TIMI $\geq 2$ ). Among the treated patients, $41.6 \%$ achieved good clinical outcomes at 30 days (defined by a 4-point or greater NIHSS improvement or mRS $\leq 2$ ). The higher baseline NIHSS score $(\geq 20)$ tended to induce a lower probability of a good outcome (mRS $\leq 2,6.3$ vs. $32.2 \%$ ) and cause higher mortality (48.5 vs. $17.6 \%$ ) compared to patients with lower NIHSS scores (less than 20). A total of 35 patients had intracranial hemorrhage on 24-hour CT; 14 (11.2\%) of them were symptomatic and the mortality was $32.8 \%$ at 90 days.

Later, the POST trial was conducted to assess the initial postmarket experience of the Penumbra System and how it compared with the results of the Penumbra Pivotal trial [102]. A total of 157 subjects were treated in 7 international centers. The mean age was 65 years and the baseline NIHSS score was 16. The median time from stroke onset to arterial puncture was $4.5 \mathrm{~h}$. Successful recanalization was observed in $87 \%$ of the treated vessels with TIMI 2 $(54 \%)$ or $3(33 \%)$. Patients who were successfully revascularized (TIMI $\geq 2$ ) by the Penumbra System had significantly better outcomes ( $\mathrm{mRS} \leq 2,45 \mathrm{vs.} 13 \%$ ) and lower mortality (16 vs. $50 \%)$ than those who were not (TIMI $\leq 1)$. Nine (5.7\%) procedural serious adverse events occurred. 
Levy et al. [103] first used self-expanding stents, including NeuroForm and Wingspan, for recanalization of acute cerebrovascular occlusions within $8 \mathrm{~h}$ of stroke onset in 18 patients. The mean age of patients from the participating institutions was 75.1 years and the median admission NIHSS score was 18 . All of the patients underwent a CT scan before the procedure. Recanalization was achieved in $79 \%$ of cases. Good outcomes ( $\mathrm{mRS} \leq 3$ ) were observed in $33 \%$ of all patients and $43 \%$ of the revascularized patients. The baseline NIHSS score did not contribute to the clinical results. Intracerebral hemorrhage occurred in a total of 7 patients; 2 of these cases resulted in progression to death, and 3 were asymptomatic and resolved on subsequent CT scans. The good clinical outcome ( 3.5 vs. $10.5 \mathrm{~h}$ ) and successful recanalization ( $8.5 \mathrm{vs} .6 \mathrm{~h}$ ) were independent of the time from stroke onset. It was noticeable that all of the 3 patients treated using Wingspan achieved complete recanalization (TIMI $\geq 2$ ). Therefore, stent-assisted recanalization in acute ischemic stroke (SARIS) used Wingspan and Enterprise (1 patient) as the primary intervention in 20 cases of acute ischemic stroke [94]. The mean age was 63 years and the mean baseline NIHSS score was 14. The mean time from stroke onset to intervention was $5.25 \mathrm{~h}$ ( 1 at $8.5 \mathrm{~h} ; 1$ at $9.75 \mathrm{~h})$. Recanalization was achieved in all of the patients (TIMI $=3,60 \%$; TIMI $=2,40 \%)$. Only 1 symptomatic and 2 asymptomatic intracranial hemorrhages occurred. At the 1-month follow-up, $60 \%$ of the patients had good clinical outcomes ( $\mathrm{mRS} \leq 3)$ and $45 \%$ of the subjects achieved complete recovery $(\mathrm{mRS} \leq 1)$. Five patients had died at the 1-month follow-up. A further study confirmed these findings [104]. Nineteen patients with acute ischemic stroke with a mean of $6.4 \mathrm{~h}$ from symptom onset were treated using 6 Enterprise and 13 Wingspan stents. The median NIHSS score on admission was 19 and the mean age was 63 years. Recanalization was achieved in $95 \%$ of occlusions (TIMI $\geq 2$ ). A good clinical outcome was achieved in $42 \%$ of cases, and 12 patients achieved an $\mathrm{mRS}$ score $\leq 3$. Symptomatic intracerebral hemorrhage occurred in 3 patients, 2 of whom died.

\section{Conclusion}

Intracranial recanalization using mechanical embolectomy is a safe and feasible approach in strictly selected patients presenting with acute ischemic stroke beyond the therapy time window for IV thrombolysis.

\section{References}

1 Tissue plasminogen activator for acute ischemic stroke - the National Institute of Neurological Disorders and Stroke rt-PA Stroke Study Group. N Engl J Med 1995;333:1581-1587.

$>2$ Furlan A, Higashida R, Wechsler L, et al: Intra-arterial prourokinase for acute ischemic stroke: the PROACT II study - a randomized controlled trial. Prolyse in Acute Cerebral Thromboembolism. JAMA 1999;282:2003-2011.

3 Bluhmki E, Chamorro A, Davalos A, et al: Stroke treatment with alteplase given 3.0-4.5 h after onset of acute ischaemic stroke (ECASS III): additional outcomes and subgroup analysis of a randomised controlled trial. Lancet Neurol 2009;8:1095-1102.

4 Reeves MJ, Arora S, Broderick JP, et al: Acute stroke care in the US: results from 4 pilot prototypes of the Paul Coverdell National Acute Stroke Registry. Stroke 2005;36:1232-1240.

$\checkmark 5$ Saver JL: Hemorrhage after thrombolytic therapy for stroke: the clinically relevant number needed to harm. Stroke 2007;38:2279-2283.

6 Saver JL: Number needed to treat estimates incorporating effects over the entire range of clinical outcomes: novel derivation method and application to thrombolytic therapy for acute stroke. Arch Neurol 2004;61:1066-1070.

7 Saver JL, Gornbein J, Grotta J, et al: Number needed to treat to benefit and to harm for intravenous tissue plasminogen activator therapy in the 3- to 4.5-hour window: joint outcome table analysis of the ECASS 3 trial. Stroke 2009;40: 2433-2437. 
$>8$ Fink JN, Kumar S, Horkan C, et al: The stroke patient who woke up: clinical and radiological features, including diffusion and perfusion MRI. Stroke 2002;33:988-993.

-9 Adeoye O, Hornung R, Khatri P, Kleindorfer D: Recombinant tissue-type plasminogen activator use for ischemic stroke in the United States: a doubling of treatment rates over the course of 5 years. Stroke 2011;42:1952-1955.

10 Wang Y, Liao X, Zhao X, et al: Using recombinant tissue plasminogen activator to treat acute ischemic stroke in China: analysis of the results from the Chinese National Stroke Registry (CNSR). Stroke 2011;42:1658-1664.

11 Abou-Chebl A: Intra-arterial therapy for acute ischemic stroke. Neurotherapeutics 2011;8:400-413.

12 Saqqur M, Uchino K, Demchuk AM, et al: Site of arterial occlusion identified by transcranial Doppler predicts the response to intravenous thrombolysis for stroke. Stroke 2007;38:948-954.

13 Riedel CH, Zimmermann P, Jensen-Kondering U, Stingele R, Deuschl G, Jansen O: The importance of size: successful recanalization by intravenous thrombolysis in acute anterior stroke depends on thrombus length. Stroke 2011;42: 1775-1777.

14 Wolpert SM, Bruckmann H, Greenlee R, Wechsler L, Pessin MS, del Zoppo GJ: Neuroradiologic evaluation of patients with acute stroke treated with recombinant tissue plasminogen activator - the rt-PA Acute Stroke Study Group. AJNR Am J Neuroradiol 1993;14:3-13.

15 Lum C, Stys PK, Hogan MJ, Nguyen TB, Srinivasan A, Goyal M: Acute anterior circulation stroke: recanalization using clot angioplasty. Can J Neurol Sci 2006;33:217-222.

16 del Zoppo GJ: Virchow's triad: the vascular basis of cerebral injury. Rev Neurol Dis 2008;5(suppl 1):S12-S21.

17 Haley EC Jr, Lyden PD, Johnston KC, Hemmen TM: A pilot dose-escalation safety study of tenecteplase in acute ischemic stroke. Stroke 2005;36:607-612.

18 Hacke W, Furlan AJ, Al-Rawi Y, et al: Intravenous desmoteplase in patients with acute ischaemic stroke selected by MRI perfusion-diffusion weighted imaging or perfusion CT (DIAS-2): a prospective, randomised, double-blind, placebo-controlled study. Lancet Neurol 2009;8:141-150.

19 Marder VJ, Jahan R, Gruber T, Goyal A, Arora V: Thrombolysis with plasmin: implications for stroke treatment. Stroke 2010;41(suppl):S45-S49.

20 Hennerici MG, Kay R, Bogousslavsky J, Lenzi GL, Verstraete M, Orgogozo JM: Intravenous ancrod for acute ischaemic stroke in the European Stroke Treatment with Ancrod Trial: a randomised controlled trial. Lancet 2006;368:18711878.

21 Sugg RM, Pary JK, Uchino K, et al: Argatroban tPA stroke study: study design and results in the first treated cohort. Arch Neurol 2006;63:1057-1062.

22 Mikulik R, Dufek M, Goldemund D, Reif M: A pilot study on systemic thrombolysis followed by low molecular weight heparin in ischemic stroke. Eur J Neurol 2006;13:1106-1111.

23 Zinkstok SM, Vermeulen M, Stam J, de Haan RJ, Roos YB: Antiplatelet therapy in combination with rt-PA thrombolysis in ischemic stroke (ARTIS): rationale and design of a randomized controlled trial. Cerebrovasc Dis 2010;29: 79-81.

24 Topol EJ: Reperfusion therapy for acute myocardial infarction with fibrinolytic therapy or combination reduced fibrinolytic therapy and platelet glycoprotein IIb/IIIa inhibition: the GUSTO V randomised trial. Lancet 2001;357: 1905-1914.

25 Alexandrov AV, Molina CA, Grotta JC, et al: Ultrasound-enhanced systemic thrombolysis for acute ischemic stroke. N Engl J Med 2004;351:2170-2178.

26 Tsivgoulis G, Zhang Y, Alexandrov AW, et al: Safety and tolerability of early noninvasive ventilatory correction using bilevel positive airway pressure in acute ischemic stroke. Stroke 2011;42:1030-1034.

27 Toda N, Tanaka T, Ayajiki K, Okamura T: Cerebral vasodilatation induced by stimulation of the pterygopalatine ganglion and greater petrosal nerve in anesthetized monkeys. Neuroscience 2000;96:393-398.

28 Barreto AD, Alexandrov AV: Adjunctive and alternative approaches to current reperfusion therapy. Stroke 2012;43: 591-598.

29 Jahan R: Solitaire flow-restoration device for treatment of acute ischemic stroke: safety and recanalization efficacy study in a swine vessel occlusion model. AJNR Am J Neuroradiol 2010;31:1938-1943.

-30 Baron JC: Perfusion thresholds in human cerebral ischemia: historical perspective and therapeutic implications. Cerebrovasc Dis 2001;11(suppl 1):2-8.

-31 Kumar G, Goyal MK, Sahota PK, Jain R: Penumbra, the basis of neuroimaging in acute stroke treatment: current evidence. J Neurol Sci 2010;288:13-24.

-32 Bardutzky J, Shen Q, Henninger N, Schwab S, Duong TQ, Fisher M: Characterizing tissue fate after transient cerebral ischemia of varying duration using quantitative diffusion and perfusion imaging. Stroke 2007;38:1336-1344.

33 Darby DG, Barber PA, Gerraty RP, et al: Pathophysiological topography of acute ischemia by combined diffusionweighted and perfusion MRI. Stroke 1999;30:2043-2052.

-34 Hacke W, Donnan G, Fieschi C, et al: Association of outcome with early stroke treatment: pooled analysis of ATLANTIS, ECASS, and NINDS rt-PA stroke trials. Lancet 2004;363:768-774.

-35 Baron JC: Mapping the ischaemic penumbra with PET: implications for acute stroke treatment. Cerebrovasc Dis 1999; 9:193-201.

36 Markus R, Reutens DC, Kazui S, et al: Hypoxic tissue in ischaemic stroke: persistence and clinical consequences of spontaneous survival. Brain 2004;127:1427-1436. 
$>37$ in predic score Programme Early CT Score. Lancet 2000;355:1670-1674.

$\$ 43$ Goyal M, Menon BK, Coutts SB, Hill MD, Demchuk AM: Effect of baseline CT scan appearance and time to recanalization on clinical outcomes in endovascular thrombectomy of acute ischemic strokes. Stroke 2011;42:93-97.

-44 Natarajan SK, Snyder KV, Siddiqui AH, Ionita CC, Hopkins LN, Levy EI: Safety and effectiveness of endovascular therapy after 8 hours of acute ischemic stroke onset and wake-up strokes. Stroke 2009;40:3269-3274.

45 Abou-Chebl A: Endovascular treatment of acute ischemic stroke may be safely performed with no time window limit in appropriately selected patients. Stroke 2010;41:1996-2000.

-46 Amenta PS, Ali MS, Dumont AS, et al: Computed tomography perfusion-based selection of patients for endovascular recanalization. Neurosurg Focus 2011;30:E6.

47 Schlaug G, Benfield A, Baird AE, et al: The ischemic penumbra: operationally defined by diffusion and perfusion MRI. Neurology 1999;53:1528-1537.

48 Kidwell CS, Alger JR, Saver JL: Evolving paradigms in neuroimaging of the ischemic penumbra. Stroke 2004;35 (suppl 1):2662-2665.

49 Parsons MW, Christensen S, McElduff P, et al: Pretreatment diffusion- and perfusion-MR lesion volumes have a crucial influence on clinical response to stroke thrombolysis. J Cereb Blood Flow Metab 2010;30:1214-1225.

50 Sanak D, Nosal V, Horak D, et al: Impact of diffusion-weighted MRI-measured initial cerebral infarction volume on clinical outcome in acute stroke patients with middle cerebral artery occlusion treated by thrombolysis. Neuroradiology 2006;48:632-639.

-51 Yoo AJ, Verduzco LA, Schaefer PW, Hirsch JA, Rabinov JD, Gonzalez RG: MRI-based selection for intra-arterial stroke therapy: value of pretreatment diffusion-weighted imaging lesion volume in selecting patients with acute stroke who will benefit from early recanalization. Stroke 2009;40:2046-2054.

52 Sobesky J, Zaro Weber O, Lehnhardt FG, et al: Which time-to-peak threshold best identifies penumbral flow? A comparison of perfusion-weighted magnetic resonance imaging and positron emission tomography in acute ischemic stroke. Stroke 2004;35:2843-2847.

53 Heiss WD: Ischemic penumbra: evidence from functional imaging in man. J Cereb Blood Flow Metab 2000;20:12761293.

54 Kaufmann AM, Firlik AD, Fukui MB, Wechsler LR, Jungries CA, Yonas H: Ischemic core and penumbra in human stroke. Stroke 1999;30:93-99.

55 Heiss WD, Kracht LW, Thiel A, Grond M, Pawlik G: Penumbral probability thresholds of cortical flumazenil binding and blood flow predicting tissue outcome in patients with cerebral ischaemia. Brain 2001;124:20-29.

-56 Liu W, Xu G, Yue X, et al: Hyperintense vessels on FLAIR: a useful non-invasive method for assessing intracerebral collaterals. Eur J Radiol 2011;80:786-791.

57 Liu W, Yin Q, Yao L, et al: Decreased hyperintense vessels on FLAIR images after endovascular recanalization of symptomatic internal carotid artery occlusion. Eur J Radiol 2011, E-pub ahead of print.

58 Lee KY, Latour LL, Luby M, Hsia AW, Merino JG, Warach S: Distal hyperintense vessels on FLAIR: an MRI marker for collateral circulation in acute stroke? Neurology 2009;72:1134-1139.

-59 Wechsler LR, Roberts R, Furlan AJ, et al: Factors influencing outcome and treatment effect in PROACT II. Stroke 2003; 34:1224-1229.

60 Patil CG, Long EF, Lansberg MG: Cost-effectiveness analysis of mechanical thrombectomy in acute ischemic stroke. J Neurosurg 2009;110:508-513.

61 Raychev R, Ovbiagele B: Endovascular therapy of acute ischemic stroke. Exp Opin Pharmacother 2011;12:913-930.

62 Balucani C, Grotta JC: Selecting stroke patients for intra-arterial therapy. Neurology 2012;78:755-761.

63 Natarajan SK, Dandona P, Karmon Y, et al: Prediction of adverse outcomes by blood glucose level after endovascular therapy for acute ischemic stroke. J Neurosurg 2011;114:1785-1799.

-64 Hallevi H, Barreto AD, Liebeskind DS, et al: Identifying patients at high risk for poor outcome after intra-arterial therapy for acute ischemic stroke. Stroke 2009;40:1780-1785.

65 Flint AC, Cullen SP, Faigeles BS, Rao VA: Predicting long-term outcome after endovascular stroke treatment: the totaled health risks in vascular events score. AJNR Am J Neuroradiol 2010;31:1192-1196.

66 Ishkanian AA, McCullough-Hicks ME, Appelboom G, et al: Improving patient selection for endovascular treatment of acute cerebral ischemia: a review of the literature and an external validation of the Houston IAT and THRIVE predictive scoring systems. Neurosurg Focus 2011;30:E7. 
Roger VL, Go AS, Lloyd-Jones DM, et al: Executive summary: heart disease and stroke statistics - 2012 update: a report from the American Heart Association. Circulation 2012;125:188-197.

-68 Standard SC, Chavis TD, Wakhloo AK, Ahuja A, Guterman LR, Hopkins LN: Retrieval of a Guglielmi detachable coil after unraveling and fracture: case report and experimental results. Neurosurgery 1994;35:994-998, discussion 999.

69 Chopko BW, Kerber C, Wong W, Georgy B: Transcatheter snare removal of acute middle cerebral artery thromboembolism: technical case report. Neurosurgery 2000;46:1529-1531.

70 Nesbit GM, Luh G, Tien R, Barnwell SL: New and future endovascular treatment strategies for acute ischemic stroke. J VascI Interv Radiol 2004;15:S103-S110.

71 Fourie P, Duncan IC: Microsnare-assisted mechanical removal of intraprocedural distal middle cerebral arterial thromboembolism. AJNR Am J Neuroradiol 2003;24:630-632.

72 Mayer TE, Hamann GF, Brueckmann HJ: Treatment of basilar artery embolism with a mechanical extraction device: necessity of flow reversal. Stroke 2002;33:2232-2235.

73 Zaidat OO, Tolbert M, Smith TP, Alexander MJ: Primary endovascular therapy with clot retrieval and balloon angioplasty for acute basilar artery occlusion. Pediatr Neurosurg 2005;41:323-327.

74 Mourand I, Brunel H, Costalat V, et al: Mechanical thrombectomy in acute ischemic stroke: catch device. AJNR Am J Neuroradiol 2011;32:1381-1385.

75 Schumacher HC, Meyers PM, Yavagal DR, et al: Endovascular mechanical thrombectomy of an occluded superior division branch of the left MCA for acute cardioembolic stroke. Cardiovasc Intervent Radiol 2003;26:305-308.

-76 Kerber CW, Wanke I, Bernard J Jr, Woo HH, Liu MW, Nelson PK: Rapid intracranial clot removal with a new device: the alligator retriever. AJNR Am J Neuroradiol 2007;28:860-863.

77 Ansari S, Rahman M, McConnell DJ, Waters MF, Hoh BL, Mocco J: Recanalization therapy for acute ischemic stroke. 2. Mechanical intra-arterial technologies. Neurosurg Rev 2011;34:11-20.

78 Henkes H, Reinartz J, Lowens S, et al: A device for fast mechanical clot retrieval from intracranial arteries (Phenox clot retriever). Neurocrit Care 2006;5:134-140.

79 Schild AF, Baltodano NM, Elias R, Livingstone J, Raines JK: Latis ${ }^{\mathrm{TM}}$ catheter: new technology for thrombectomy of vascular access grafts. J Vasc Access 2003;4:118-122.

80 Berlis A, Lutsep H, Barnwell S, et al: Mechanical thrombolysis in acute ischemic stroke with endovascular photoacoustic recanalization. Stroke 2004;35:1112-1116.

81 Owens CA: Ultrasound-enhanced thrombolysis: EKOS EndoWave Infusion Catheter System. Semin Intervent Radiol 2008;25:37-41.

82 Lee MS, Singh V, Wilentz JR, Makkar RR: AngioJet thrombectomy. J Invasive Cardiol 2004;16:587-591.

83 Molina CA, Saver JL: Extending reperfusion therapy for acute ischemic stroke: emerging pharmacological, mechanical, and imaging strategies. Stroke 2005;36:2311-2320.

84 Muller-Hulsbeck S, Grimm J, Leidt J, Jahnke T, Heller M: Comparison of in vitro effectiveness of mechanical thrombectomy devices. J Vasc Interv Radiol 2001;12:1185-1191.

85 Bose A, Henkes H, Alfke K, et al: The Penumbra System: a mechanical device for the treatment of acute stroke due to thromboembolism. AJNR Am J Neuroradiol 2008;29:1409-1413.

86 Liu X, Xu G: Endovascular treatments of atherosclerotic carotid diseases in China. Int J Stroke 2010;5:417-420.

87 Yue X, Xi G, Zhou Z, Xu G, Liu X: Combined intraarterial and intravenous thrombolysis for severe cerebral venous sinus thrombosis. J Thromb Thrombolysis 2010;29:361-367.

88 Yue X, Yin Q, Xi G, et al: Comparison of BMSs with SES for symptomatic intracranial disease of the middle cerebral artery stenosis. Cardiovasc Intervent Radiol 2011;34:54-60.

89 Zhu SG, Zhang RL, Liu WH, et al: Predictive factors for in-stent restenosis after balloon-mounted stent placement for symptomatic intracranial atherosclerosis. Eur J Vasc Endovasc Surg 2010;40:499-506.

$\$ 90$ Brott TG, Hobson RW 2nd, Howard G, et al: Stenting versus endarterectomy for treatment of carotid-artery stenosis. N Engl J Med 2010;363:11-23.

$\checkmark 91$ Levy EI, Ecker RD, Horowitz MB, et al: Stent-assisted intracranial recanalization for acute stroke: early results. Neurosurgery 2006;58:458-463, discussion 458-463.

92 Levy EI, Ecker RD, Hanel RA, et al: Acute M2 bifurcation stenting for cerebral infarction: lessons learned from the heart - technical case report. Neurosurgery 2006;58:E588, discussion E588.

-93 Fitzsimmons BF, Becske T, Nelson PK: Rapid stent-supported revascularization in acute ischemic stroke. AJNR Am J Neuroradiol 2006;27:1132-1134.

$\checkmark 94$ Levy EI, Siddiqui AH, Crumlish A, et al: First Food and Drug Administration-approved prospective trial of primary intracranial stenting for acute stroke: SARIS (stent-assisted recanalization in acute ischemic stroke). Stroke 2009;40: 3552-3556.

$\$ 95$ Weber W, Bendszus M, Kis B, Boulanger T, Solymosi L, Kuhne D: A new self-expanding nitinol stent (Enterprise) for the treatment of wide-necked intracranial aneurysms: initial clinical and angiographic results in 31 aneurysms. Neuroradiology 2007;49:555-561.

96 Machi P, Costalat V, Lobotesis K, et al: Solitaire FR thrombectomy system: immediate results in 56 consecutive acute ischemic stroke patients. J Neurointerv Surg 2012;4:62-66.

97 Caloro M, Lionetto L, Cuomo I, et al: An improved simple LC-MS/MS method for the measurement of serum aripiprazole and its major metabolite. J Pharm Biomed Anal 2012;62:135-139. 
98 Mendonca N, Flores A, Pagola J, et al: Trevo System: single-center experience with a novel mechanical thrombectomy device. J Neuroimaging 2011, E-pub ahead of print.

-99 Gobin YP, Starkman S, Duckwiler GR, et al: MERCI 1: a phase 1 study of mechanical embolus removal in cerebral ischemia. Stroke 2004;35:2848-2854.

100 Smith WS, Sung G, Saver J, et al: Mechanical thrombectomy for acute ischemic stroke: final results of the Multi MERCI trial. Stroke 2008;39:1205-1212.

101 Penumbra Pivotal Stroke Trial Investigators: The penumbra pivotal stroke trial: safety and effectiveness of a new generation of mechanical devices for clot removal in intracranial large vessel occlusive disease. Stroke 2009;40:2761-2768.

102 Tarr R, Hsu D, Kulcsar Z, et al: The POST trial: initial post-market experience of the Penumbra system: revascularization of large vessel occlusion in acute ischemic stroke in the United States and Europe. J Neurointerv Surg 2010;2: 341-344.

103 Levy EI, Mehta R, Gupta R, et al: Self-expanding stents for recanalization of acute cerebrovascular occlusions. AJNR Am J Neuroradiol 2007;28:816-822.

104 Linfante I, Samaniego EA, Geisbusch P, Dabus G: Self-expandable stents in the treatment of acute ischemic stroke refractory to current thrombectomy devices. Stroke 2011;42:2636-2638. 